\title{
Extremadura representada de los medios de comunicación. Intertextualidad y estereotipos
}

\author{
$M^{\mathrm{a}}$ Cristina CAÑamero Alvarado \\ Facultad Ciencias de la Comunicación Universidad CJC \\ ccanamero@ucjc.edu
}

\section{Resumen:}

La primera mitad del siglo XX es rica en manifestaciones iconográficas en los medios de Comunicación, una zona concreta, Extremadura, se convierte en objeto iconográfico en portadas, revistas o documentales.

Tres obras son claves para la expansión de los referentes iconográficos: Ruth M. Anderson, In the lands of Extremadura, Luis Buñuel Las Hurdes: Tierra sin Pan y Spanish Village: It lives at ancient poverty and faith, W. Eugene Smith.

El objetivo que se plantea es mostrar las líneas de intertextualidad que contienen las imágenes del estudio a través de las representaciones visuales.

Palabras Clave: Intertextualidad; Imagen; Extremadura; Referentes Iconográficos; Comunicación.

\section{Extremadura represented in the media. Intertextuality and stereotypes}

\begin{abstract}
:
The first half of the twentieth century is rich in iconographic manifestations in the mass media, a particular area, Extremadura, becomes iconographic object covers, magazines and documentaries. Three works are key to the expansion of iconographic references: Ruth M. Anderson, In the lands of Extremadura, Luis Buñuel The Hurd: Land Without Bread and Spanish Village: It lives at ancient poverty and faith, W. Eugene Smith.

The objective set is to show intertextuality lines containing study images through visual representations.
\end{abstract}

Key Words: Intertextuality; Image; Extremadura; Iconographic References; Communication.

Referencia normalizada:

Cañamero Alvarado, M. C. (2014): Extremadura representada de los medios de comunicación. Intertextualidad y estereotipos. Historia y Comunicación Social. Vol. 19. Núm. Especial Marzo. Págs. 351-362.

Sumario: 1. Introducción; 2. Espacio y Tiempo de representación; 3. La imagen audiovisual: intertextos y textos visuales; 4. Análisis; 5. Conclusiones; 6. Referencias Bibliográficas.

\section{Introducción}

La imagen juega un papel prioritario dentro de la sociedad actual, es un reflejo de ella, en realidad ha sido una protagonista casi omnipresente en la vida de occidente 
desde el nacimiento del primer tipo de imagen fija perdurable, la Heliografía. A lo largo del texto abordamos el tema, recurrente en el mundo de la imagen, de la composición en sí misma, punto de controversia, en las creaciones artísticas y dentro de los estudios de Comunicación Audiovisual, poniendo en tela de juicio la originalidad y la naturalidad, o instantaneidad de algunas imágenes.

Se recogen ejemplos de trabajos creativos con un contenido de representaciones iconográficas fácilmente reconocibles, en diversos formatos, aunque por la época en la que fueron publicadas las obras que se van a analizar lo hicieron en formatos tradicionales, cine, prensa o libros.

La elección de las fotografías y fotogramas para el análisis, así como el corte de la época, obedece a un motivo práctico y de necesidad para poder acotar temporal y técnicamente, documentos gráficos no manipulados digitalmente, pertenecientes a una era analógica y a un segmento concreto de la historia del siglo XX, en su primera mitad, donde el fotoperiodismo y los documentales antropológicos o sociológicos tuvieron gran importancia dentro de los Medios de Comunicación, los autores de referencia fueron protagonistas en ellas.

Los autores que se han elegido para elaborar el análisis lo han sido por la calidad y la importancia de su obra en el momento de su creación y su posterior difusión mundial, pudiendo ser extrapolable y aplicable la metodología, desde el punto de vista estético, histórico y cultural a otros grupos de imágenes.

Todos ellos parten de un conocimiento previo de la zona a través de escritos o de obras audiovisuales anteriores, lo que les condicionan y ponen los cimientos a la hora de crear su propio proyecto.

Comenzaremos por la autora norteamericana Ruth Matilda Anderson, importante en su época por la realización de numerosos reportajes de carácter antropológico y sociológico en diferentes puntos de la geografía española. Seguiremos con Luis Buñuel, a cuya biografía poco podemos añadir, para el estudio de la obra del gran cineasta aragonés se ha procurado la reinterpretación de la historiografía existente a través de la obra elegida para el análisis. Y seguiremos con W. Eugene Smith, al que dedicaremos un apartado especial y un análisis más detallado, no sólo de su obra de fotoensayo en general, sino de "Spanish Village" en particular. Todos ellos, por desgracia desaparecidos, en un momento de su vida profesional tuvieron una vinculación extraordinaria con la tierra de Cáceres, punto de unión del estudio iconográfico de este trabajo.

Con el fin de evitar una reiteración a la hora de mencionarlos a lo largo del presente trabajo, a partir de ahora los autores seleccionados serán nombrados con siglas, que corresponden a sus nombres y apellidos: Ruth Matilda Anderson (R.M.A.), Luis Buñuel (L.B.), W. Eugene Smith (W.E.S.). 


\section{Espacio y tiempo de representación.}

En general, para los que nunca habían pisado tierras extremeñas la imagen era de una tierra árida, pobre y abrupta, de gentes cerradas y algo faltas de entendimiento, construida sobre la base de información que ser forjó en estas décadas, extrapolando algunos de los aspectos mencionados sobre la comarca de Las Hurdes a las demás comarcas cacereñas. Pero la realidad es bien distinta, la riqueza natural, cultural y humana de la región ha sido demostrada a lo largo de las últimas décadas, convirtiéndose en uno de los puntos de referencia del turismo de nuestro país, y máxime con la evolución social y cultural que se ha producido en esta tierra.

Es complicado en unos pocos años borrar la huella de la imagen forjada a lo largo de los siglos en torno a la región extremeña, reforzada por el empobrecimiento de postguerra y la emigración de sus gentes a las zonas industriales de España.

Desde el viaje que realizó Mauricio Legendre a las Hurdes, hasta las últimas imágenes aparecidas de Deleitosa en los medios de comunicación nacionales, en el año 2011, media un siglo, el siglo XX, con motivo de Photoespaña, que en el caso de España tiene unas connotaciones políticas y sociales muy peculiares, pues hemos pasado por cuatro sistemas de gobierno muy diferenciados política y socialmente, monarquía, república, dictadura y por fin democracia con monarquía parlamentaria.

Se hace necesaria una ubicación en el tiempo y en el espacio. Entender las condiciones socioeconómicas de un momento histórico determinado nos permite poder intentar comprender cómo un producto audiovisual se generó en un momento determinado, condicionado no sólo por la sociedad, sino también por la política, los movimientos estéticos,..., todo lo que nos hace ser lo que somos, ser hijos de nuestra época.

\section{La imagen audiovisual: intertextos y textos visuales.}

Siguiendo la idea de Zavala (Zavala, 2003), podemos decir que la imagen es como un espejo donde se proyecta, se reconoce y se recrea la propia identidad a través del ejercicio de sensibilidad. Lo que se apuesta, la propia sensibilidad, la experiencia y la memoria, es decir, la identidad como visión del mundo está determinado por un lapso de tiempo, y por la atención que dedicamos al visionado de las imágenes.

La prensa a principios del siglo XX se desarrolla de un modo formidable por diversas cuestiones, tales como el avance en los medios de impresión que van incorporando progresivamente la imagen, nuevos medios de comunicación, como el cinematógrafo, junto con el progresivo reconocimiento de la libertad de expresión, lo que fomenta el crecimiento del público receptor.(Gutiérrez Espada, 1982).

Los espectadores esperan obtener algo valioso a cambio de su tiempo y su atención, aunque lo más importante es la experiencia que va acumulándose en su memoria. 
Lo que hace cada uno de nosotros, a partir de esta experiencia personal, generamos expectativas particulares ante cada nueva experiencia audiovisual la acumulación de experiencias o la retención de información audiovisual en nuestra memoria, es un acto relativamente espontáneo (Sontag, 2003).

El mensaje visual no es una propuesta estética, sino la materialización de una simbiosis cultural que debe asimilarse e interpretarse en el contexto en que se implanta y desarrolla (Fontcuberta, 1984), en el caso planteado, podernos ceñirnos a estudiar de forma particular una imagen pero nunca podremos desposeerla de las circunstancias que la hicieron posible. Es lo que se ha dado en llamar Sociología Visual (De Miguel \& Pinto, 2002), siguiendo a los profesores Carmelo Pinto y J.M de Miguel. Ahondando en los documentos audiovisuales que han retratado la tierra de Extremadura encontramos diferentes trabajos, de los cuales el más interesante, por su repercusión mediática y controversia, sería el de "Spanish Village"(MNAC), realizado por W.E.S. para la revista Life en $1950^{1}$.

El mensaje iconográfico se establece por influencia social y con el objetivo de influir socialmente pretende persuadir, informar, remover conciencias con su diálogo, tanto sí hablamos de una imagen fija, una fotografía, como sí nos referimos a una imagen en movimiento, cinematógrafo (Gubern, 2001).

Examinar si la imagen crea o refleja los estereotipos sociales (De Miguel \& Pinto, 2002), y localizar las causas de que dichos estereotipos aparezcan de forma constante en las referencias visuales del siglo XX (Freund, 2001), son motivos seductores e interesantes para este trabajo de investigación.

No obstante, el campo histórico de actuación de la imagen o de los medios audiovisuales es bastante extenso y conviene acotar el período de estudio. De este modo, teniendo en cuenta los diversos cambios económicos, políticos, sociales y culturales que ha soportado España en las primeras décadas del s. XX, la etapa de análisis y estudio se delimitan en los últimos años del reinado de Alfonso XIII, la II República y dos primeras décadas del franquismo, pues constituye un interesante momento por su contexto y complejidad.

Desde el punto de vista de la composición argumental podemos encontrar paralelismos entre las diferentes obras escritas, audiovisuales y gráficas de algunos autores que se detallan a continuación, no por ello siendo las únicas en las que podemos encontrar dichas referencias iconográficas:

- Mauricio Legendre, “Las Jurdes. Étude de géographie humaine” 1927

- Ruth Matilda Anderson

- Revistas impresas que detallan la primera visita de Alfonso XIII a las Hurdes

- Segunda visita de Alfonso XIII a las Hurdes.

- Documental “Las Hurdes: Tierra sin Pan" Buñuel

- Gerald Brenand por España 
- W. Eugene Smith

En el plano compositivo, estas imágenes no son únicas y exclusivas de nuestro país, en las décadas de los 30, 40 y 50 han dejado buena muestra de este tipo de imágenes por todo el mundo:

- F.S.A., Farm Security Administration

- Henri Cartier-Bresson

- Marc Riboud

Por tanto, el objeto de este estudio es un recorrido parcial, pues se ha escogido una muestra representativa de autores, por la forja de la imagen política y social de España, y más concretamente de Extremadura ante el mundo desde principios del siglo XX hasta la década de los 50.

No se justifica su modo de actuar al presentar los tipos humanos, por qué su forma de ver España y de transmitirla al resto del mundo nos afectará en nuestro afán de proyección al exterior, en un intento de atraer divisas en los años más aperturistas de la Dictadura. La imagen de una España sumida en la miseria y sobre todo una imagen que se asemeja más a la España decimonónica es lo que se refleja en las fotografías y en los escritos con los que habitualmente acompañaba sus ensayos fotográficos.

La imagen es uno de los mejores soportes que hay para la memoria (Freund, 2001), nos trae al presente retazos del pasado o nos lleva a un lugar que nunca hemos visitado, mostrándonos rostros de personas desconocidas que invitamos a entrar en nuestros hogares, por tanto los hacemos formar parte de nuestras vidas. Nos permite conservar fragmentos del pasado, imágenes que no volverán a repetirse (Op.Cit., 2001), y que incluso han desaparecido y gracias ella no lo olvidaremos, conservándolo todo el tiempo que la técnica nos permita.

En los primeros años de existencia de la imagen fija, y posteriormente de la imagen en movimiento, el estudio del texto audiovisual no puede disociarse del análisis de la técnica y de las influencias artísticas provenientes de la pintura en el primer caso y del teatro, en el segundo, pero puesto que el método de estudio de caso que nos ocupa está situado a partir de la segunda década del siglo XX, estas primitivas influencias han ido desapareciendo en gran medida. Aunque se siga con rigor la metodología planteada y se busque una justificación teórica en todas aquellas afirmaciones que se planteen.

El eminente carácter "subjetivo" que subyace en todas las investigaciones históricas, al no poder tener un testimonio de primera mano de los protagonistas, estará latente, sobre todo cuando se describan las directrices del contexto histórico en el que se desenvuelven los autores y, por tanto, sus obras creativas. Al venir ligados con unas décadas especialmente convulsas en la historia del siglo XX, donde la cultura, al igual que ha sucedido en otras épocas de la humanidad, va a sufrir la interacción de factores externos como serán el estadio o las Guerras Mundiales. 
La cultura, o lo que es entendido por contexto cultural, esos factores que rodean el desarrollo creativo de los movimientos artísticos, se van a describir, más que definir, como un estado o hábito mental que puede convertirse en una forma de vida íntimamente vinculada a los retos y dilemas de la sociedad, en esta caso concreto de la Sociedad Contemporánea, la descripción de Durkheim sobre vida social, da una explicación a este hecho:

La vida social reposa sobre un sustrato que está determinado tanto en su tamaño como en su forma. Lo que lo constituye es la masa de los individuos que componen la sociedad, el modo como están distribuidos sobre el terreno y la naturaleza y la configuración de las cosas de todo tipo que afectan a las relaciones colectivas. (Durkheim, 2012, pág. 247)

Que sería una analogía de las directrices clásicas de Beaumont Newhall, que en 1937 en su "Historia de la Fotografia" (Newhall, 2002), aplica agrupando la producción de los fotógrafos por escuelas o estilos, lo mismo que se hace con la división del cine en géneros. De ahí que la muestra elegida sean imágenes que manifiestan una directriz común, son "documentales reales" de una sociedad determinada.

Lo que nos viene a confirmar una de nuestras ideas iniciales, la composición de una imagen, su intertextualidad viene dada en muchas ocasiones, y en gran medida, por nuestra cultura o tradición iconográfica. Se entiende como intertextualidad en su sentido más amplio, la co-presencia de dos o más elementos (textos visuales) o el conjunto de elementos que nos acercan a otro, del mismo autor o de diferente procedencia, que pueden ser coincidentes en su época de creación, o no (Marinkovich \& Benítez, 2004).

Se han expuesto las dificultades que conlleva enfrentarse a la elaboración de una base que sustente el análisis propuesto de imágenes, todas ellas unidas por lo que se denomina "Intertextualidad", una de las limitaciones metodológicas y teóricas con las que nos topamos, son que las referencias que podemos aportar del término son hechas en base al texto, no al texto visual, que es el que nos ocupa en el estudio de caso.

Para que la relación del intertexto visual tenga la capacidad de ratificar el enunciado del presente capítulo que se plantean como punto de partida de la investigación, creemos necesario que el estudio se despliegue a través de un marco de conceptos teóricos en ciencias sociales, que ayudarán a la conexión y comprensión de las ideas planteadas en los siguientes capítulos, la Semiótica, siguiendo nuestra línea clásica de autores y referencias, utilizaremos como guía para las aportaciones en este campo a Umberto Eco, (Eco, 2011), en Sociología otro de las campos que ya se han citado y que se erige como esencial en muchos de los estudios en ciencias sociales Durkheim con su método sociológico, es aplicable a la época en la que se enmarcan las imágenes objeto de estudio, (Durkheim, 2012),...., esta orientación metodológica, extendida entre los estudios relacionados con la historia y la imagen, se aleja de los estudios y métodos aplicados en otros ámbitos de estudio, más preocupados por la acumulación de la información de una manera empírica y técnica, soslayando la implicación social 
y de estilo, imprescindibles desde el punto de vista del estudio que se plantea y la ficha a la que nos adaptaremos.

No podemos dejar de lado la perspectiva tecnológica, que condiciona la difusicón de la información, pensando en la presentación clásica del esquema Laswell, necesario para poder entender el texto visual, pues debemos conocer tanto la naturaleza del mensaje (Herrero, 2009), como de su emisor y receptor, tratando a los autores como emisores, a los espectadores como receptores y a la muestra de análisis como el mensaje cuando se analice del texto visual.

De los tres grupos de imágenes que se han elegido como muestra para el estudio, se debe tener en cuenta que la fuente de la que provienen son:

- Formatos: Cinematógrafo y Fotografía

- Tiempo: provienen de décadas diferentes, lo que también condiciona la técnica aplicada.

- Finalidad: las imágenes obtenidas tendrán distinta finalidad, una exposición documental, exhibición cinematográfica y un ensayo fotográfico para prensa escrita.

La definición de técnica más adecuada al enfoque dado al presente estudio sería:

Método y procedimiento práctico (incluido sus medios) para obtener una obra y sus resultados", mientras que la tecnología: "el estudio de la técnica como elemento de la cultura (Gutierrez Espada, 1991, pág. 23).

Este hándicap tecnológico, pues se tratan de distintas técnicas, cuya explicación de forma escrita a un neófito en la materia conllevaría una desviación considerable del tema propuesto, hace que el estudio desde este punto de vista no sea absolutamente determinante, la intertextualidad, pues tanto el método de captura como la finalidad de la imagen obtenida no tienen un hilo conductor o una finalidad común.

\section{Análisis.}

Se sustenta sobre un marco teórico transdisciplinar ${ }^{2}$, en el que tienen cabida los elementos necesarios para comprender la función social de la imagen audiovisual desde su nacimiento hasta la actualidad, especialmente a mediados del siglo XX, cuándo la información y el crecimiento de los medios de comunicación de masas hace que la utilización de la imagen se generalice, convirtiéndose en una variable importante dentro de la percepción social y la generación de estereotipos.

Realizado este planteamiento, en el análisis de la obra de estos tres autores, se realiza el análisis individual de las muestras de imágenes seleccionadas, haciendo una revisión más en profundidad de las que corresponden a W.E.S., para realizar una 
aproximación de las cuestiones planteadas, formando así el cuerpo de la presente investigación.

Uno de los propósitos del estudio es el análisis en conjunto de las imágenes, para comprobar que la costumbre y la memoria iconográfica occidental vive y pervive en las representaciones visuales, sobre todo cuando éstas están llamadas a despertar el lado sensible y la empatía del receptor. Las imágenes que utilizan no deben valorarse solamente por su alto contenido estético, también por su carácter informativo, puesto que en los dos casos de estudio más difundidos, L.B. y W.E.S., el primero pertenece al género del documental cinematográfico y el segundo está definido como un foto-ensayo, integrándose dentro del fotoperiodismo. En el caso de R.M.A., podemos decir que constituye un documento etnográfico y antropológico, pero dadas las características de la formación de la autora, en la década de los años 20 cuando la fotografía social, antecedente del fotoperiodismo cobraba auge, revisten a su trabajo de un cariz documental.

En todos los casos la imagen va unida a un texto, de forma audiovisual o escrita convirtiéndose en elementos interrelacionados, lo que en muchas ocasiones nos ayuda a contextualizar dicha imagen (Villafañe, 2006).

El análisis de las obras siguiendo la metodología propuesta por el grupo de Investigación ITACA-UJI, grupo de investigación de la Universidad Jaume I de Castellón (Universitat Jaume I), obedece a la necesidad de tener unas tablas claras, al ser el grueso de las reflexiones fruto de un análisis cualitativo de las imágenes. A través de este análisis tendremos una visión de cómo se percibía la realidad sociopolítica de España en los años que se tratan de nuestro país. (Marzal Felici, 2010)

El primero los conceptos estudiados plantea el nivel contextual de las imágenes, datos generales, parámetros técnicos y biografía del autor, así como un apartado con los datos que serán relevantes en torno a la época y lugar dónde se tomó la fotografía. El segundo concepto parte del estudio del nivel morfológico de la fotografía, apreciaciones sobre la escala, forma, textura, nitidez,..., que ayudan a dilucidar las condiciones en las que fue realizada la toma. El tercer punto analizado retoma aspectos técnicos de la imagen, pero desde un nivel compositivo, estudiando el orden icónico, distribución..., características sintácticas o compositivas de la imagen que permiten en la reflexión generales. En el cuarto punto se presenta el nivel interpretativo de la imagen y las relaciones intertextuales de la misma, uno de los puntos más importantes para sustentar los objetivos del presente estudio (Zunzundegui, 2007).

Los grupos de análisis que se han planteado, y que vendrían a aglutinar las tendencias iconográficas de los autores referenciados:

- Infraestructuras: estrategias de creación o re-escenificación de "paisajes vivientes", algo habitual en las representaciones iconográficas, la composición en este grupo de imágenes mediante la construcción o reconstrucción de las escenas es un rasgo común. La intertextualidad viene dada por uno de los elementos iconográficos, no por la imagen en conjunto, el agua, rodeada de 
personajes secundarios, pero que la erigen como protagonista al ser un bien necesario para la existencia. Aunque es un elemento que se convierte en una excusa para introducir otros elementos que nos conmueven y que se analizan a continuación, las mujeres y los niños.

- Infancia: las imágenes que representan pobreza suelen llamar la atención, más cuando son niños. Si bien la apariencia compositiva puede no dar un primer punto de conexión, la intertextualidad viene dada no sólo por el objeto iconográfico, los niños, si no por la percepción y la sensación, el universo de los sentimiento que se despiertan ante la infancia. Niños en situación de carestía y precariedad.

- Maternidad: la imagen audiovisual es heredera iconográfica de las artes anteriores, representando la imagen femenina como icono en toda su extensión, en este grupo de análisis adopta la pose de maternidad, una mujer con un pequeño en brazos como centro de la composición. La comprensión del texto visual es inmediata, dejando patentes relaciones intertextuales, no sólo entre la muestra presentada, si no con las representaciones iconográficas de nuestra tradición cristiana.

- Vivienda: motivo iconográfico común, imágenes costumbristas, arquitecturas toscas de adobe y pizarra, situadas en el último plano, anteponiendo figuras humanas. Las líneas vienen dadas por las construcciones. Todas ellas parecen no ser fruto de la casualidad, mostrando una preparación que equilibra la escena. Las relaciones intertextuales en esta secuencia de imágenes se establecen no sólo por los elementos compositivos, sino también por su carga simbólica, de representación, mostrando la sencillez de la vida, sin que parezca evolucionar en 30 años.

\section{Conclusiones.}

Extremadura ha estado presente en el devenir de la Historia mediante su representación involuntaria en documentos escritos y audiovisuales de repercusión internacional. Como si fuera un convidado de piedra, se utilizó para ejemplificar el retraso de España con respecto al resto de Europa y del primer mundo en general.

El análisis de la imagen es un proceso metódico reglado que se mide con indicadores como la composición, el mensaje iconográfico, la forma, todo ello conforma el mensaje, la textualidad que será leída por el receptor. Los textos visuales estudiados en los grupos del análisis nos muestran rasgos comunes, fácilmente identificables no sólo por el objeto iconográfico común, también por su similitud compositiva.

La imagen, es una ventana que representa la realidad, cuando se abre se puede ver el exterior, el objetivo es mostrar el mundo convirtiéndose en una copia de él, acercando lo desconocido, mejor que con una descripción literaria del lugar o de sus 
gentes. Los autores estudiados que retrataron la vida y las gentes de Extremadura las mostraron al mundo con unas formas y tipos determinados, generando unos estereotipos visuales que han sobrevivido, unos textos visuales que todavía hoy se reconocen.

La imagen se ha erigido como un fiel reflejo de la sociedad, ha aglutinado en sus entrañas metamórficas, a través de las técnicas y formas de representación los cambio y evoluciones del ser humano. Reflejo que llega a la sociedad a través de los medios de Comunicación en sus diferentes formatos, el texto visual, en sus dos representaciones clásicas de imagen, fotografía y cinematógrafo.

No obstante, dejan clara la intencionalidad del autor, proyectando la precepción de la realidad, comunicando de manera visual su pensamiento.

Las imágenes nos hablan, nos muestran aspectos de otra persona o lugares, con el paso del tiempo, y la repetición del objeto iconográfico, se convierten en algo que forma parte de nuestra vida o memoria. No obstante, como instrumento de persuasión podemos afirmar que en su estructura más íntima de producción, la captación de la realidad se ha regido siempre por unos cánones previamente establecidos, que si bien han sido acordes a los cambios del sistema, siempre han estado supeditados a unos nexos de unión que enmascaraban o disfrazaban las características más arraigadas de la figura humana en cuanto a distinción, diferencia y discriminación.

La imagen es como un espejo donde se proyecta, se reconoce y se recrea la propio identidad a través del ejercicio de sensibilidad, lo que se apuesta, la propio sensibilidad, la experiencia y la memoria, es decir, la identidad como visión del mundo, está determinado por un lapso de tiempo y por la atención que dedicamos al visionado de las imágenes.

\section{Bibliografía}

\subsection{Libros:}

BUÑUEL, L. (1982). Mi último suspiro. Barcelona: Plaza \&Janés.

DE MIGUEL, J. M., \& PINTO, C. (2002). Sociología Visual. (CIS, \& S. XXI, Edits.) Madrid, España.

DURKHEIM, É. (2012). Las reglas del método sociológico y otros escritos. Madrid: Alianza.

ECO, U. (2011). La Estructura Ausente. Introducción a la Semiótica. Barcelona: DeBolsillo .

FONTCUBERTA, J. (1984). El Beso de Judas . Barcelona : Gustavo Gili.

FREUND, G. (2001). La fotografía como documento social. Barcelona, España: Gustavo Gili.

GUBERN, R. (2001). Historia del Cine. Lumen.

GUTIERREZ ESPADA, L. (1991). La función social de la Imagen Audiovisual. Madrid, España: UCM. 
HERRERO, J. C. (2009). Manual de Teoría de la Información y de la Comunicación. (J. C. HERRERO, Ed.) Madrid, España: Universitas.

MARZAL FELICI, J. (2010). Cómo se lee una fotografía. Interpretaciones de una mirada. Madrid, España: Ediciones Cátedra.

NEWHALL, B. (2002). Historia de la Fotografía. Barcelona: Gustavo Gili.

SONTAG, S. (2003). Ante el dolor de los demás . Madrid: Alfaguara.

VILLAFAÑE, J. (2006). Introducción a la teoría de la imagen. Madrid, España: Ediciones Pirámide.

ZUNZUNEGUI, S. (2007). Pensar la Imagen. Madrid: Cátedra.

6.2 Capítulos o artículos en libros o revistas en papel:

MARINKOVICH, J., \& Benítez, R. (2004). Aproximaciones al análisis intertextual del discurso científico. Revista signos , 33 (48), 117-128.

MNAC. (1999). W. Eugene Smith. Barcelona: MNAC.

6.3 Artículos en publicaciones web:

Universitat Jaume I. (s.f.). analisisfotografia.uji.es Propuesta de Modelo de Análisis de Imagen. Recuperado el 12 de 08 de 2008, de http://www.analisisfotografia.uji. es/root $2 /$ intr $2 . h t m l$

ZAVALA, L. (2003). Elementos del discurso cinematográfico . Unidad Xochimilco: Universidad Autónoma Metropolitana.

ASOLETO. (s.f.). Deleitosa. Recuperado el 08 de 2003, de http://asoleto.free.fr/ deleitosa/spaniendorf.htm

GARRA, L. (s.f.). http://www.lucasgarra.com/. Recuperado el 09 de 2011, de http:// www.lucasgarra.com/

Interviú. (1988). www. interviú.es. Obtenido de http://www.interviu.es/

The Nebraska Society. (2005). (N. P. Miller, Productor) Recuperado el 01 de 09 de 2010, de http://www.usgennet.org/usa/ne/topic/resources/OLLibrary/Nebraskana/pages/nbka0008.htm

BRISSET MARTÍN, D. E. (01 de 01 de 2006). "Las Hurdes" de Buñuel. Aproximación desde la antropología visual. Recuperado el 05 de 09 de 2007, de http://hdl. handle.net/10481/7085

\section{Notas}

1 Imágenes publicadas en Norteamérica, no sólo en la publicación periódica de la revista Life, también lo serían en un facsímil posterior.

2 La idea de transdisciplinaridad se basa en la integración de las diferentes disciplinas científicas. Al utilizar este término, no demasiado común, puesto que multidisplinar o interdisciplinar suelen ser los que se han usado tradicionalmente en estudios que engloban distintas áreas de ciencias sociales, lo que se pretende es mostrar que en el análisis de imágenes, las áreas de estudio planteadas, no son elementos independientes, si no que se unen e incluso difuminan sus límites. La Universidad de Plymouth, ha desarrollado en la última década una investigación basada en la idea de transdisciplinaridad y transculturalidad, http://www.plymouth.ac.uk/research/273 


\section{La autora}

María Cristina Cañamero Alvarado. Doctora Ciencias de la Comunicación, Universidad CJC. Licenciada en Historia Facultad de Filosofía y Letras UAM. Profesora en la Facultad de Ciencias de la Comunicación Universidad CJC desde el curso académico 2001/2002, áreas de Historia de los Medios de Comunicación/Teoría e Historia de la Imagen. 